\title{
Autopoiesis in digital learning design: Theoretical implications in education
}

\author{
Claudio Aguayo ${ }^{1}$ \\ ${ }^{1}$ Auckland University of Technology \\ claudio.aguayo@aut.ac.nz
}

\begin{abstract}
Today's mobile and smart technologies have a key role to play in the transformative potential of educational practice. However, technology-enhanced learning processes are embedded within an inherent and unpredictable complexity, not only in the design and development of educational experiences, but also within the socio-cultural and technological contexts where users and learners reside. This represents a limitation with current mainstream digital educational practice, as digital experiences tend to be designed and developed as 'one solution fits all' products, and/or as 'one-off' events, failing to address ongoing socio-technological complexity, therefore tending to decay in meaningfulness and effectiveness over time. One ambitious solution is to confer the processes associated with the design and development of digital learning experiences with similar autopoietic properties found within living systems, in particular adaptability and self-organisation. The underpinning rationale is that, by conferring such properties to digital learning experiences, intelligent digital interventions responding to unpredictable and ever-changing socio-cultural conditions can be created, promoting meaningful learning over-time. Such an epistemological view of digital learning aims to ultimately promote a more efficient type of design and development of digital learning experiences in education.
\end{abstract}

\section{Introduction: Autopoiesis in digital learning}

Digital technology has proven to enhance learning outcomes across educational sectors and contexts, providing great potential for achieving societal transformation (Cook \& Santos, 2016; Pachler, Benchair \& Cook, 2010). Current smart mobile technology allows learning to occur practically anywhere in collaboration with anyone (Cochrane, 2011); promote innovative (Parsons, 2013), inclusive (Traxler, 2010) and transformative (Lindsay, 2015) types of learning, thereby challenging traditional pedagogical approaches (Merchant, 2012). Mobile learning can fit individual characteristics and needs (Aguayo, 2016) through self-driven learning (Hase and Kenyon, 2013) while addressing local societal challenges (Aguayo and Eames, 2017). Yet critical challenges remain, notably: minimising the decay of digital interventions over time; and achieving widespread learning outcomes in diverse and multicultural audiences (Dunn and Marinetti, 2008; Hennessy, 2019).

One ambitious solution may lie in the theoretical concept of autopoiesis coming from systems biology. Autopoiesis, literally meaning self-making, defines living organisms as self-organising units, capable of adapting to unpredictable changes in their environments while maintaining internal coherence over time (Maturana and Varela, 1980). The focus here is on organisational processes rather than structural components. Since its introduction more than four decades ago, the fundamental ideas of autopoiesis have been transferred and explored across disciplines, including psychology, creative arts, economy, and sociology (Hallowell, 2009; Razeto-Barry, 2014), yet they still remain to be fully explored and applied in the field of technology-enhanced learning.

The Santiago School of Cognition, founded on the concept of autopoiesis, considers the adaptive capacity of living systems towards their environment as an intelligent cognitive process (Maturana and Varela, 1980). But most importantly, it establishes that human experience and cognition are unique to every individual and context (Thompson, 2007). This can have profound epistemological consequences when designing digital technology in education, as the dominant 'one solution fits all' paradigm becomes invalid. On the contrary, digital technology and their associated educational processes on learners ought to provide as many intelligent solutions as individuals and contexts there are over-time, via adaptability and self-organisation (Aguayo, 2018). How can this be achieved? The solution may lie in replicating autopoietical principles and processes during the design and development of digital learning experiences (Aguayo, Veloz and RazetoBarry, 2019). Yet the focus here is on the paradigm shift when it comes to designing digital learning experiences for a complex audience residing in an ever-changing complex environment.

\section{Theoretical implications in education}

From the perspective of the Santiago school, embedding digital learning systems with properties found in living systems could, in theory, create 'intelligent' educational interventions capable of promoting and facilitating the emergence of learning while responding to ongoing sociocultural changes. This could reduce the amount of time and resources required to maintain digital learning interventions over time, as the current trend is to develop one-off events, many times without long-term considerations or planning. In theory, developing digital learning experiences containing autopoietic properties would contribute to the efficient design and use of digital technology resources and products in 
education, which in turn can contribute to overcoming current societal challenges.

Another theoretical premise derived from the Santiago school is that all types of experiences are unique and belonging to the individual and to the moment and context. Therefore, as users interact with intelligent and adaptable digital learning systems (through their 'user interface' UI), the coming together of such interaction between two learning actors (Sumara and Davis, 1997), or 'structural coupling' (Jorg, 2000; Maturana and Varela, 1980), produces the emergence of a unique 'user experience' (UX as known in digital design) bodily lived and experienced by the user; and from where the digital system could cognate to re-adapt and self-organise its structure and functioning to ongoingly facilitate such interaction over-time. The key point to make here is that, in consequence, such a view of UX in digital learning design implies that only user interfaces can be designed and created, with user experiences occurring as an unpredictable emergence of the interaction between users and UI. Yet the current dominating practice in digital learning design is that both UI/UX can be targeted and designed for, with the 'one solution fits all' paradigm still dominating. Such paradigm is invalid from the perspective of the Santiago school of cognition, as user experiences are unpredictable, and unique to the individual, the learning situation, and the shared coming together between the digital UI and the user, and therefore cannot be designed for, but facilitated and nurtured. This has profound implications to the current practice of digital learning design in education.

The underlying theoretical and conceptual rationale for the inclusion of autopoietic principles in digital learning design, development and implementation can ultimately contribute to current societal challenges through promoting and facilitating meaningful educational outcomes and experiences over-time. But more importantly, this epistemological view of technology-facilitated user experience invites us to reconsider and reconceptualise the role of digital learning systems and tools in educational practice.

\section{References}

Aguayo, C. (2018). Exploring autopoietic principles in technologyenhanced learning. In paper presented at the Inaugural Scholarship of Technology-Enhance Learning 2018 Symposium, 15-16 February, AUT South Campus, Auckland, New Zealand: SoTEL. Accessible https://www.researchgate.net/publication/324329272 Exploring _autopoietic_principles_in_technology-enhanced_learning

Aguayo, C. (2016). Activity theory and community education for sustainability: When systems meet reality. In D. Gedera \& J. Williams (Eds.), Activity Theory in Education: Research and practice (pp. 139-151). Rotterdam: Sense.

Aguayo, C., Veloz, T., \& Razeto-Barry, P. (2019). Autopoietic principles and processes in the development of digital affordances in education. In preparation. Preprint accessible at: https://www.researchgate.net/publication/331192949_Autopoieti c_principles_and_processes_in_the_development_of_digital_aff ordances_in_education
Cochrane, T. (2011). mLearning: Why? What? Where? How. In Proceedings of the 28th ASCILITE Conference, ASCILITE(pp. 250-262).

Cook, J., \& Santos, P. (2016). Three phases of mobile learning state of the art and case of mobile help seeking tool for the health care sector. In D. Churchill, J. Lu, T. K. F. Chiu, \& B. Fox (Eds.), Mobile learning design (pp. 315-333). Singapore: Springer.

Dunn, P., \& Marinetti, A. (2008). Beyond localization: Effective learning strategies for cross-cultural e-learning. In H. Rahman (Ed.), Developing successful ICT strategies: competitive advantages in a global knowledge-driven society (pp. 155-164). London: Information Science Reference.

Hallowell, R. (2009). Humberto Maturana and Francisco Varela's Contribution to Media Ecology: Autopoiesis, The Santiago School of Cognition, and Enactive Cognitive Science. In P. A. Soukup (Ed.), Proceedings of the Media Ecology Association (pp. 143-158). Saint Louis, MO: Media Ecology Association. Retrieved from:

Hennessy, S., Mavrikis, M., Girvan, C., Price, S., \& Winters, N. (2019). BJET Editorial for the 50th Anniversary Volume in 2019: Looking back, reaching forward. British Journal of Educational Technology, 50(1), 5-11. https://doi.org/10.1111/bjet.12731

Jorg, T. (2000). About the unexpected: complexity of learning based on reciprocity and human agency. Chaos and complexity theory: Special interest newsletter. Retrieved 8 June, 2009, from http://www.udel.edu/aeracc/library/Fallo0.htm

Lindsay, Lucie. (2015). Transformation of teacher practice using mobile technology with one-to-one classes: M-learning pedagogical approaches. British Journal of Educational Technology, n/a-n/a. doi: 10.1111/bjet.12265

Maturana, H. R., \& Varela, F. J. (1980). Autopoiesis and cognition. The realization of the living. Dordrecht, Boston, London: D. Reidel Publishing Company.

Merchant, G. (2012). Mobile practices in everyday life: Popular digital technologies and schooling revisited. British Journal of Educational Technology, 43(5), 770-782. doi:10.1111/j.14678535.2012.01352.x

Pachler, N., Bachmair, B., \& Cook, J. (2010). Mobile Learning: Structures, agency, practices. Boston, MA: Springer US. Retrieved from http://link.springer.com/10.1007/978-1-44190585-7

Parsons, David (Ed.). (2013). Innovations in mobile educational technologies and applications. Hershey, PA: IGI Global.

Razeto-Barry, P. (2012). Autopoiesis 40 years Later. A Review and a Reformulation. Origins of Life and Evolution of Biospheres, 42(6), 543-567. doi:10.1007/s11084-012-9297-y

Sumara, D., \& Davis, B. (1997). Enactivist theory and community learning: Toward a complexified understanding of action research. Educational Action Research, 5(3), 403-422.

Thompson, E. (2007). Mind in life: Biology, phenomenology, and the sciences of mind. Cambridge, MA: Belknap/Harvard Univ. Press.

Traxler, John. (2010). Will student devices deliver innovation, inclusion, and transformation? Journal of the Research Center for Educational Technology (RCET), 6(1), 3-15. 